\title{
Inverse Association of Lipoprotein (a) With Markers of Insulin Resistance in Dyslipidemic Subjects
}

\author{
H. VAVERKOVÁ ${ }^{1}$, D. KARÁSEK ${ }^{1}$, M. HALENKA ${ }^{1}$, L. CIBÍČKOVÁ ${ }^{1}$, V. KUBÍČKOVÁ ${ }^{2}$ \\ ${ }^{1}$ Third Department of Internal Medicine - Nephrology, Rheumatology and Endocrinology, Faculty \\ of Medicine and Dentistry, Palacky University, Olomouc, Czech Republic, ${ }^{2}$ Department of Clinical \\ Biochemistry, University Hospital, Olomouc, Czech Republic
}

Received November 16, 2016

Accepted December 16, 2016

\begin{abstract}
Summary
Lipoprotein (a) $[\mathrm{Lp}(\mathrm{a})]$ is an LDL-like particle that contains an apolipoprotein B100 molecule covalently bound to a plasminogen-like glycoprotein, apolipoprotein (a) [apo(a)]. Epidemiological evidence supports a direct and causal association between $L p(a)$ levels and coronary risk. On the contrary, a few prospective findings demonstrate inverse association of $L p(a)$ levels with risk of type 2 diabetes (T2DM). The aim of our study was to evaluate the association of $L p(a)$ with indicators of insulin resistance (IR) and metabolic syndrome (MS), which precede development of T2DM. We enrolled 607 asymptomatic dyslipidemic subjects (295 men and 312 women, mean age $45.6 \pm 14.0$ years) into our cross-sectional study. $\mathrm{Lp}(\mathrm{a})$ concentrations correlated inversely with TG, AIP, insulin, HOMA, C-peptide, BMI, waist circumference, and number of MS components ( $p<0.01$ for all). Subjects with MS had significantly lower $L p(a)$ concentrations in comparison with those without the presence of this phenotype $(p<0.0001)$. Serum concentrations of $L p(a)$ in the lower $\left(1^{\text {th }}-3^{\text {rd }}\right)$ quartiles of insulin and HOMA were significantly higher than in the $4^{\text {th }}$ quartile of these insulin resistance markers $(p<0.001)$. Odds ratios of having increased markers of IR (TG, HOMA) and MS in top quartile of $L p(a)$ also indicate inverse association of $L p(a)$ with IR. The results of our study support an inverse association of $L p(a)$ levels with IR and MS that precedes overt T2DM diagnosis.
\end{abstract}

\section{Key words}

Dyslipidemia • Insulin resistance • Lipoprotein (a) • Metabolic syndrome $\bullet$ Type 2 diabetes mellitus

\section{Corresponding author}

H. Vaverková, Third Department of Internal Medicine Nephrology, Rheumatology and Endocrinology, University Hospital Olomouc, I. P. Pavlova 6, 77900 Olomouc, Czech Republic. Fax:+420588442526. E-mail: helena.vaverkova@fnol.cz

\section{Introduction}

Lipoprotein (a) $[\mathrm{Lp}(\mathrm{a})]$ is a plasma lipoprotein consisting of a cholesterol-rich LDL particle with one additional protein - apolipoprotein (a), attached via a disulfide bond to apolipoprotein B100 (Utermann 1989). The plasma levels of $\mathrm{Lp}(\mathrm{a})$ are under strong genetic control via variations in the lipoprotein (a) [LPA] gene, especially the LPA kringle IV 2 repeats, which encode apo(a) and exist in multiple copies (Boerwinkle et al. 1992)

The interindividual range of $\mathrm{Lp}(\mathrm{a})$ concentrations is very wide from less than $0.1 \mathrm{mg} / \mathrm{dl}$ to more than $300 \mathrm{mg} / \mathrm{dl}$. Few people lack Lp(a) in their plasma. The broad range in $\mathrm{Lp}(\mathrm{a})$ distribution is known for all populations and is highly skewed towards low levels in most ethnic groups (Kronenberg 2016).

$\mathrm{Lp}(\mathrm{a})$ blood concentrations are primarily determined by the apo(a) gene, LPA, (Boerwinkle et al. 1992) and are negligibly affected by lifestyle modifications, such as diet and exercise. It is also commonly accepted that plasma $\mathrm{Lp}(\mathrm{a})$ levels remain relatively stable over an individual's lifetime (Marcovina et al. 1994, Nordestgaard et al. 2010).

Both serum Lp(a) levels (Ergou et al. 2009, Danesh et al. 2000) and LPA gene variants (Kamstrup et 
al. 2009, Clarke et al. 2009) have been reported to be strongly associated with the risk of CVD.

Surprisingly, recent studies found that serum $\mathrm{Lp}$ (a) concentrations are inversely associated with T2DM (Mora et al. 2010, Kamstrup and Nordestgaard 2013, Ye et al. 2014), pre-diabetes, insulin resistance and metabolic syndrome (Ding et al. 2015, Sung et al. 2013, Marzano et al. 2014). The potential reasons for an inverse association between $\mathrm{Lp}(\mathrm{a})$ and T2DM are unknown. Some animal studies suggest an effect of insulin in reducing $L p(a)$ levels (Neele et al. 1999). Thus Lp(a) might be another lipoprotein, that is associated with metabolic syndrome characterized by insulin resistance.

As there are some differences in $\mathrm{Lp}(\mathrm{a})$ levels, distribution patterns, and a slightly different association of $\mathrm{Lp}$ (a) with risk of CHD in various racial/ethnic groups (Guan et al. 2015), it seems reasonable to study pathophysiological associations of this unique lipoprotein in various populations.

We examined the association of $\mathrm{Lp}(\mathrm{a})$ with markers of insulin resistance and metabolic syndrome in asymptomatic dyslipidemic Caucasian subjects of European ancestry.

\section{Methods}

\section{Study design and subjects}

The study was carried out as a cross-sectional study on asymptomatic dyslipidemic subjects who had been examined at the Lipid Center of the $3^{\text {rd }}$ Department of Internal Medicine, University Hospital Olomouc, Czech Republic. All the dyslipidemic subjects filled out a questionnaire on their medical history, especially their cardiovascular status, medication and smoking habits. All the subjects were tested for an underlying cause of secondary hyperlipidemia: diabetes mellitus, hypothyroidism, hepatic or renal impairment, and nephrotic syndrome. Subjects with these diagnoses were not enrolled in the study. Other exclusion criteria were a history of clinically manifest atherosclerosis (coronary artery disease, cerebrovascular ischemic disease, and peripheral arterial disease), hypolipidemic treatment in the previous six weeks, and the clinical presence of acute infectious disease or trauma. Dyslipidemia was defined as total cholesterol $>5 \mathrm{mmol} / \mathrm{l}$ or triglycerides (TG) $>1.5 \mathrm{mmol} / 1$ or both. Most authorities recommend TG level $\geq 1.7 \mathrm{mmol} / 1$ for definition of hypertriglyceridemia. The reason why we have chosen the TG level $>1.5 \mathrm{mmol} / \mathrm{l}$ is justified by the fact that the clinical definition of the most common familial dyslipidemia, the so called familial combined hyperlipidemia, is based (besides other requirements) on concomitant presence of ApoB $>1.2 \mathrm{~g} / 1$ and TG $>1.5 \mathrm{mmol} / \mathrm{l}$ in several family members (de Graaf et al. 2004). Furthermore, small dense LDL start to increase at the TG level $>1.5 \mathrm{mmol} / 1$ (Campos et al. 1992). Nevertheless, in our cohort only 5 subjects had TG levels in the range $1.5-1.7 \mathrm{mmol} / \mathrm{l}$.

Six hundred and seven subjects (295 men and 312 women, mean age $45.6 \pm 14.0$ years) fulfilled the above-mentioned criteria and were included in the study. The study was reviewed and approved by the Institutional Ethics Committee of the Medical Faculty and University Hospital and informed consent was obtained from all participants.

\section{Anthropometric and laboratory measurements}

The body mass index (BMI), waist circumference (WC), systolic (SBP), and diastolic (DBP) blood pressure were determined. The WC was measured in the standing position, at the middle point between the anterior iliac crest and the lower border of the ribs. The auscultatory method of BP measurement with a properly calibrated and validated mercury sphygmomanometer was used. At least three sitting BP measurements were taken at 30-s intervals and the mean of the last two was calculated. Patients treated with antihypertensive drugs or with $\mathrm{SBP} \geq 140$ or $\mathrm{DBP} \geq 90 \mathrm{~mm} \mathrm{Hg}$ were assumed to be hypertensive.

For a diagnosis of MS we used a harmonized definition (Alberti et al. 2009). The presence of any three of five risk factors constitutes a diagnosis of MS: elevated WC (WC $\geq 102 \mathrm{~cm}$ in men and $\geq 88 \mathrm{~cm}$ in women); triglycerides $\geq 1.7 \mathrm{mmol} / 1$ (drug treatment for elevated TG is an alternative indicator - not present in our cohort); reduced HDL-C $<1.0 \mathrm{mmol} / 1$ in men and $<1.3 \mathrm{mmol} / 1$ in women (drug treatment for reduced HDL-C is an alternative indicator - not present in our cohort); elevated blood pressure (systolic $\geq 130$ and/or diastolic $\geq 85 \mathrm{~mm} \mathrm{Hg}$ or antihypertensive drug treatment in a patient with a history of hypertension), and elevated fasting glucose $\geq 5.6 \mathrm{mmol} / 1$ (drug treatment of elevated glucose is an alternative indicator - not present in our cohort).

\section{Biochemical analyses}

Venous blood samples were drawn in the morning after a 12-h fast. Total cholesterol (TC), 
triglycerides (TG), and HDL-cholesterol (HDL-C) were determined enzymatically on a Modular SWA analyzer (Roche, Basel, Switzerland) using commercially available kits (Cholesterol SYS 917, Triglycerides GPO-PAP and HDL cholesterol plus, third-generation kits, Roche, Basel, Switzerland). The determination of HDL-C was performed by a direct method without precipitation of lipoproteins containing apoB. LDL-C levels were calculated according to the Friedewald formula (Friedewald et al. 1972) in subjects with $\mathrm{TG} \leq 4.5 \mathrm{mmol} / \mathrm{l}$ (77 subjects had TG levels $>4.5$ and LDL-C was not calculated). Therefore, we calculated the non-HDL cholesterol (non-HDL-C $=$ TC - HDL-C). Atherogenic index of plasma (AIP) was calculated as a $\log$ (TG/HDL-C) with TG and HDL-C expressed in molar concentrations. This index was proposed by Dobiasova and Frohlich (2001) and Frohlich and Dobiasova (2003). The concentration of apolipoprotein B (ApoB) and apolipoprotein A1 (apoA1) was determined immunoturbidimetrically on a Modular SWA analyzer (TinaQuant Apo A1, TinaQuant Apo B kits, all Roche, Basel, Switzerland). Lipoprotein (a) [Lp(a)] was determined immunoturbidimetrically using a Lipoprotein (a) Tina-Quant TQ kit (Roche, Basel, Switzerland). Glycemia was determined by means of the enzymatic-colorimetric method (Glucose GOD-PAP kit) on a Modular SWA analyzer. Insulin was determined using commercially available kits - Insuline (Immunotech, Marseille, France) using specific antibodies by the IRMA (immunoradiometric assay) method. The result obtained was then used for the calculation of the parameter of insulin resistance HOMA [homeostasis model assessment: fasting glycemia $(\mathrm{mmol} / \mathrm{l}) *$ fasting insulin $(\mathrm{mU} / \mathrm{l}) / 22.5]$. C-peptide was determined using commercially available kits - C-peptide (Immunotech, Marseille, France) using specific antibodies by the IRMA method. Concentrations of insulin and C-peptide were measured in the serum stored at $-80{ }^{\circ} \mathrm{C}$.

\section{Statistical analyses}

All the values are expressed as means $\pm \mathrm{SD}$ or as median (interquartile range) for variables with non-normal distribution. The Kolmogorov-Smirnov test was used to test for normal distribution. Variables with a non-normal distribution ( $\mathrm{Lp}(\mathrm{a}), \mathrm{TG}$, insulin, HOMA, C-peptide) were log-transformed to normalize their distribution before statistical analysis. The differences between the groups were analyzed using ANCOVA and adjusted for age and sex, and age, sex, and BMI. Relationships between continuously distributed values were examined by Spearman's correlation coefficient. Logistic regression analysis was used to determine the odds ratio (OR) and $95 \%$ CIs of having increased markers of insulin resistance ( $4^{\text {th }}$ quartile) and MS in a top quartile of $\mathrm{Lp}(\mathrm{a})$ compared to $\mathrm{Lp}(\mathrm{a})$ quartile 1. Statistical analysis was performed using SPSS for Windows version 12.0 (Chicago, Illinois, USA). Due to multiple testing of the data, probability values of $\mathrm{P}<0.01$ were considered statistically significant.

Table 1. Clinical and biochemical characteristics of dyslipidemic subjects.

\begin{tabular}{|c|c|}
\hline Parameter & $\begin{array}{c}\text { Mean } \pm \text { SD or median } \\
\text { (interquartile range) }\end{array}$ \\
\hline$N(M / F)$ & $607(295 / 312)$ \\
\hline Age (years) & $45.6 \pm 14.0$ \\
\hline$B M I\left(\mathrm{~kg} / \mathrm{m}^{2}\right)$ & $26.3 \pm 4.0$ \\
\hline Waist (cm) & $88.3 \pm 12.6$ \\
\hline$S B P(m m H g)$ & $129.3 \pm 15.5$ \\
\hline$D B P(m m H g)$ & $79.7 \pm 8.7$ \\
\hline$T C(\mathrm{mmol} / \mathrm{l})$ & $6.73 \pm 1.64$ \\
\hline$L D L-C(\mathrm{mmol} / \mathrm{l})^{*}$ & $4.17 \pm 1.28$ \\
\hline$A p o B(g / l)$ & $1.23 \pm 0.32$ \\
\hline$H D L-C(\mathrm{mmol} / \mathrm{l})$ & $1.44 \pm 0.45$ \\
\hline$T G(\mathrm{mmol} / \mathrm{l})$ & $1.91(1.32 ; 2.98)$ \\
\hline$A I P \log (T G / H D L-C)$ & $0.13(-0.09 ; 0.4)$ \\
\hline Non-HDL-C (mmol/l) & $5.28 \pm 1.68$ \\
\hline$H D L-C(\mathrm{mmol} / \mathrm{l})$ & $1.44 \pm 0.45$ \\
\hline ApoA1 $(g / l)$ & $1.57 \pm 0.34$ \\
\hline$A p o B(g / l)$ & $1.23 \pm 0.32$ \\
\hline $\operatorname{Lp}(a)(g / l)$ & $0.18(0.07 ; 0.56)$ \\
\hline Glucose ( $\mathrm{mmol} / \mathrm{l})$ & $5.13 \pm 0.82$ \\
\hline Insulin (mIU/l) & $7.90(5.40 ; 11.20)$ \\
\hline HOMA & $1.75(1.14 ; 2.65)$ \\
\hline C-peptide $(m g / l)$ & $2.28(1.60 ; 3.08)$ \\
\hline$M S(N ; \%)$ & $199 ; 32.7 \%$ \\
\hline
\end{tabular}

Data are means \pm SD or medians (interquartile range) for skewed variables, $\mathrm{n}$ (number) and $\%$ for categorical variables. * LDL-C was calculated in 530 subjects according to Friedewald equation.

\section{Results}

The clinical and biochemical characteristics of the whole group are summarized in Table 1. 
In the whole group, $\mathrm{Lp}(\mathrm{a})$ correlated inversely with TG $(p<0.001)$, AIP $(p<0.001)$, insulin $(p<0.005)$, HOMA $(p<0.005)$, BMI $(p<0.001)$, waist circumference $(p<0.005)$, and number of MS components $(p<0.001)$. On the contrary, a positive correlation between $\mathrm{Lp}(\mathrm{a})$ and HDL-C $(p<0.05)$, and ApoB $(p<0.05)$ was found. Negative correlation of $\mathrm{Lp}(\mathrm{a})$ with $\mathrm{TG}$ and positive correlation with HDL-C indicates that $\mathrm{Lp}(\mathrm{a})$ shows an inverse relationship with the atherogenic dyslipidemia characteristically associated with insulin resistance.

The results according to lipoprotein (a) quartiles are summarized in Table 2. Significant differences between quartiles of $\mathrm{Lp}$ (a) were found for TG, AIP, BMI, and prevalence of MS. Most prominent differences were found for TG, AIP, and prevalence of MS which persisted after adjustment for age, sex, and BMI.

Table 2. Characteristics of participants according to $L p(a)$ quartiles.

\begin{tabular}{|c|c|c|c|c|c|}
\hline Parameter & $\begin{array}{c}\text { Lp(a) } \\
\text { quartile I }\end{array}$ & $\begin{array}{c}\text { Lp(a) } \\
\text { quartile II }\end{array}$ & $\begin{array}{l}\text { Lp(a) } \\
\text { quartile III }\end{array}$ & $\begin{array}{l}\text { Lp(a) } \\
\text { quartile IV }\end{array}$ & Statical significance \\
\hline Lipoprotein (a) & 0.034 & 0.121 & 0.311 & 0.952 & \\
\hline$(g / l)$ & $(0.012 ; 0.059)$ & $(0.098 ; 0.149)$ & $(0.238 ; 0.401)$ & $(0.745 ; 1.189)$ & \\
\hline Age (years) & $44.8 \pm 13.4$ & $47.3 \pm 13.7$ & $45.3 \pm 14.8$ & $45.3 \pm 14.0$ & \\
\hline$B M I\left(\mathrm{~kg} / \mathrm{m}^{2}\right)$ & $27.1 \pm 4.4$ & $26.6 \pm 4.1$ & $25.6 \pm 3.7$ & $25.9 \pm 3.5$ & $\mathbf{p}<\mathbf{0 . 0 1}$ (I vs. III; I vs. IV) \\
\hline Waist (cm) & $89.9 \pm 13.5$ & $89.5 \pm 13.4$ & $87.1 \pm 12.0$ & $86.5 \pm 11.0$ & $\mathrm{p}<0.05$ (I vs. III; I vs. IV) \\
\hline$S B P(m m H g)$ & $129.3 \pm 15.3$ & $131.5 \pm 15.2$ & $128.7 \pm 15.4$ & $127.6 \pm 15.6$ & NS \\
\hline$T C(\mathrm{mmol} /)$ & $6.87 \pm 2.09$ & $6.67 \pm 1.54$ & $6.79 \pm 1.53$ & $6.66 \pm 1.35$ & NS \\
\hline$L D L-C(\mathrm{mmol} / \mathrm{l})$ & $4.06 \pm 1.27$ & $4.02 \pm 1.17$ & $4.40 \pm 1.41$ & $4.23 \pm 1.25$ & NS \\
\hline Apo B $(g / l)$ & $1.20 \pm 0.33$ & $1.21 \pm 0.29$ & $1.28 \pm 0.35$ & $1.24 \pm 0.29$ & NS \\
\hline$H D L-C(\mathrm{mmol} / \mathrm{l})$ & $1.38 \pm 0.46$ & $1.49 \pm 0.47$ & $1.42 \pm 0.42$ & $1.49 \pm 0.41$ & NS \\
\hline$T G(\mathrm{mmol} / \mathrm{l})$ & $\begin{array}{c}2.32 \\
(1.50 ; 4.21)\end{array}$ & $\begin{array}{c}1.85 \\
(1.29 ; 3.26)\end{array}$ & $\begin{array}{c}1.74 \\
(1.29 ; 2.38)\end{array}$ & $\begin{array}{c}1.77 \\
(1.27 ; 2.58)\end{array}$ & $\begin{array}{l}\quad \mathbf{p}<\mathbf{0 . 0 0 1 *} \\
(\text { I vs. II; I vs. III; I vs. IV) }\end{array}$ \\
\hline $\begin{array}{l}A I P \\
\log (T G / H D L-C)\end{array}$ & $0.31 \pm 0.47$ & $0.168 \pm 0.33$ & $0.132 \pm 0.32$ & $0.096 \pm 0.33$ & $\begin{array}{l}\quad \mathbf{p}<\mathbf{0 . 0 0 1 *} \\
(\text { I vs. II; I vs. III; I vs. IV) }\end{array}$ \\
\hline Glucose (mmol/l) & $5.23 \pm 1.18$ & $5.08 \pm 0.64$ & $5.14 \pm 0.72$ & $5.04 \pm 0.64$ & NS \\
\hline Insulin (mIU/l) & $\begin{array}{c}8.50 \\
(6.1 ; 12.2)\end{array}$ & $\begin{array}{c}8.1 \\
(5.8 ; 12.2)\end{array}$ & $\begin{array}{c}7.6 \\
(5.3 ; 10.3)\end{array}$ & $\begin{array}{c}7.45 \\
(4.6 ; 10.1)\end{array}$ & $\begin{array}{c}\qquad \mathrm{p}<0.05 \\
\text { (I vs. III; I vs. IV; II vs. III; II vs. IV) }\end{array}$ \\
\hline HOMA & $\begin{array}{c}1,87 \\
(1.23 ; 3.00)\end{array}$ & $\begin{array}{c}1.82 \\
(1.22 ; 2.74)\end{array}$ & $\begin{array}{c}1.72 \\
(1.13 ; 2.42)\end{array}$ & $\begin{array}{c}1.61 \\
(1.08 ; 2.29)\end{array}$ & $\begin{array}{c}\mathrm{p}<0.05 \\
(\text { I vs. III; I vs. IV) }\end{array}$ \\
\hline C-peptide $(m g / l)$ & $\begin{array}{c}2.55 \\
(1.67 ; 3.44)\end{array}$ & $\begin{array}{c}2.36 \\
(1.57 ; 3.10)\end{array}$ & $\begin{array}{c}2.15 \\
(1.53 ; 2.92)\end{array}$ & $\begin{array}{c}2.20 \\
(1.69 ; 2.90)\end{array}$ & NS \\
\hline
\end{tabular}

Data are means \pm SD or medians (interquartile range) for skewed variables. P was calculated using ANCOVA after adjustment for age and sex, persistence of statistical significance after adjustment for age, sex, and BMI is expressed by *. $\mathrm{P}<0.01$ is considered statistical significant (written in bold).

Serum concentrations of $\mathrm{Lp}(\mathrm{a})$ (expressed as mean and interquartile range) in the lower $\left(1^{\text {th }}-3^{\text {rd }}\right)$ quartiles of insulin and HOMA were significantly higher (both $\mathrm{p}<0.001$ ) than in the $4^{\text {th }}$ quartile of these insulin resistance markers: for insulin $\operatorname{Lp}(\mathrm{a}) 0.209$ (0.083; 0.627) vs. 0.129 (0.059; 0.363); for HOMA Lp(a) 0.213 (0.085; $0.625)$ vs. $0.126(0.059 ; 0.338)$. Significance persisted after adjustment for age and sex, for HOMA after adjustment for age, sex, and BMI.

Subjects with MS had significantly lower Lp(a) concentrations in comparison with those without the presence of this cardiometabolic risk phenotype: 0.126 (0.059; 0.325$)$ vs. $0.242(0.089 ; 0.682), \mathrm{p}<0.0001$. This significance persisted after adjustment for age, sex, and BMI $(\mathrm{p}<0.001)$.

The odds ratios of having increased markers of insulin resistance (TG and HOMA) and MS in the top quartile of $\mathrm{Lp}(\mathrm{a})$ also indicate an inverse association of $\mathrm{Lp}$ (a) with insulin resistance (Table 3). 
Table 3. Odds ratios of having increased markers of insulin resistance ( $4^{\text {th }}$ quartile), and MS in a top quartile of $L p(a)$ in comparison with the $1^{\text {th }}$ quartile.

\section{$\begin{array}{ccc}\text { Odds ratio } & \text { Significance }\end{array}$}

\begin{tabular}{lcc}
\hline \multirow{2}{*}{ TG } & $0.378(0.222 ; 0.645)$ & $\mathbf{p}<\mathbf{0 . 0 0 1}$ \\
& $0.361(0.206 ; 0.632)$ & $\mathbf{p} *<\mathbf{0 . 0 0 1}$ \\
Insulin & $0.527(0.307 ; 0.906)$ & $\mathrm{p}<0.05$ \\
& $0.532(0.309 ; 0.918)$ & $\mathrm{p}^{*}<0.05$ \\
HOMA & $0.452(0.261 ; 0.782)$ & $\mathbf{p}<\mathbf{0 . 0 1}$ \\
& $0.454(0.261 ; 0.789)$ & $\mathbf{p}^{*}<\mathbf{0 . 0 1}$ \\
C-peptide & $0.575(0.339 ; 0.976)$ & $\mathbf{p}<0.05$ \\
& $0.577(0.339 ; 0.982)$ & $\mathrm{p}^{*}<0.05$ \\
MS & $0.309(0.184 ; 0.516)$ & $\mathbf{p}<\mathbf{0 . 0 0 1}$ \\
& $0.285(0.167 ; 0.487)$ & $\mathbf{p}^{*}<\mathbf{0 . 0 0 1}$ \\
\hline
\end{tabular}

Lp(a) - lipoprotein (a), TG - triglycerides, HOMA - [homeostasis model assessment: fasting glycemia $(\mathrm{mmol} / \mathrm{l}) *$ fasting insulin $(\mathrm{mU} / \mathrm{l}) / 22.5], \mathrm{MS}$ : harmonized definition of MS (Alberti et al. 2009), p - statistical significance without adjustment, p* statistical significance after adjustment for age and sex. As multiple testing of the data was performed, only $p<0.01$ was considered as significant (written in bold).

\section{Discussion}

In our study, we observed an inverse association of serum $\mathrm{Lp}$ (a) concentrations with markers of insulin resistance (TG, AIP, insulin, HOMA, BMI, waist circumference, and number of MS components), and MS, characteristically associated with insulin resistance. In agreement with this, significant differences were found in TG, AIP, HOMA, BMI, and prevalence of MS between quartiles of $\mathrm{Lp}(\mathrm{a})$. Prevalence of MS decreased from the lowest to the top quartile of $\mathrm{Lp}(\mathrm{a})$.

This is in agreement with recently published studies. Sung et al. (2013) described the inverse association between $\mathrm{Lp}$ (a) levels and metabolic syndrome and its components in a large Asian South Korea cohort. Similarly inverse association between serum $\mathrm{Lp}(\mathrm{a})$ and type 2 diabetes, prediabetes, and insulin resistance was described in the Chinese population (Ding et al. 2015). Marzano et al. (2014) described independent inverse association between insulin resistance (according to HOMA) and Lp(a) blood levels in 527 hypertensive patients of the Italian population.

In Czech population, Zlatohlavek et al. (2008) evaluated association of $\mathrm{Lp}(\mathrm{a})$ with increased risk of atherosclerosis in patients with multiple other risk factors.
They demonstrated a significantly elevated Lp(a) levels in patients with coronary heart disease. Nevertheless, they did not evaluate either markers of insulin resistance or metabolic syndrome. Lp(a) levels of 70 T2DM patients of their cohort did not differ from non-diabetics.

An inverse association between $\mathrm{Lp}(\mathrm{a})$ and measures of glucose and insulin in a population of Mexican Americans having a high prevalence of non-insulin-dependent diabetes mellitus was even described in 1998 by Rainwater and Haffner (1998). Their glucose-intolerant individuals had significantly lower Lp(a) concentrations and a significant increase of residual apo(a) size. Haffner et al. (1995) also observed a positive correlation between insulin sensitivity and Lp(a) levels in normoglycemic men. Until recently, little attention has been paid to this issue as $\mathrm{Lp}(\mathrm{a})$ was not a therapeutic target at this time.

Large scale prospective studies and meta-analysis data show that increased Lp(a) levels are a risk factor for CVD (Bennet et al. 2008, Kamstrup et al. 2008, Ergou et al. 2009, Danesh et al. 2000). Mendelian randomization analyses in two human genetic association studies provide support for a probable causal role of elevated $\mathrm{Lp}(\mathrm{a})$ in the development of cardiovascular disease in the general population (Kamstrup et al. 2009, Clarke et al. 2009).

Elevated Lp(a) levels may increase the risk of CVD/CHD: i) via accelerated atherogenesis as a result of intimal deposition of $\mathrm{Lp}$ (a) cholesterol, ii) via binding of proinflammatory oxidized phospholipids to $\mathrm{Lp}(\mathrm{a})$, iii) via prothrombotic/anti-fibrinolytic effects as the apolipoprotein(a) possesses structural homology with both plasminogen and plasmin (but has no fibrinolytic activity), or iiii) via all these mechanisms (Kroneberg 2016). The association of $\mathrm{Lp}(\mathrm{a})$ with $\mathrm{CVD} / \mathrm{CHD}$ risk in general population is continuous without a threshold or dependence on LDL- or non-HDL-cholesterol levels (Kamstrup et al. 2008).

Patients with T2DM have a two- to four-fold higher cardiovascular risk than the non-diabetics (Almdal et al. 2004). Surprisingly, Lp(a) probably does not play any role in this high risk. Prospective study of healthy US women (Women's Health Study [WHS]) revealed inverse association between $\mathrm{Lp}(\mathrm{a})$ and the risk of incident T2DM (Mora et al. 2010). Moreover, data from Copenhagen City Heart Study and the Copenhagen General Population Study also showed that low concentrations of $\mathrm{Lp}$ (a) were associated with a risk of T2DM (Kamstrup and Nordestgaard 2013) and similar findings were observed 
in EPIC-Norfolk cohort (Ye et al. 2014). However, Mendelian randomization studies, that used genetic variant rs10455872 elevating $\mathrm{Lp}$ (a) levels as an instrument, did not support a causal association of $\mathrm{Lp}(\mathrm{a})$ with the risk of T2DM (Kamstrup and Nordestgaard 2013, Ye et al. 2014). Nevertheless, a causal association for large lipoprotein (a) isoform size with T2DM cannot be excluded (Kamstrup and Nordestgaard 2013). According to Kronenbegr (2016) SNP rs10455872 is an imprecise instrument to support or exclude causality of low $\mathrm{Lp}$ (a) levels for T2DM. Better genetic instruments are probably necessary to clarify this issue.

Furthermore, prospective study of two cohorts of T2DM from Nurses' Health Study and the Health Professional Follow-Up Study support the notion that the effect of $\mathrm{Lp}(\mathrm{a})$ on CVD risk among diabetic patients might be different from that in the general population. Qi et al. (2012) evaluated relationship between genetic loci influencing $\mathrm{Lp}(\mathrm{a})$, plasma $\mathrm{Lp}(\mathrm{a})$ levels, and cardiovascular disease risk among diabetic patients and compared it with the observations in the general population. They did not find any significant association between plasma levels of $\mathrm{Lp}(\mathrm{a})$ and CVD incidence in T2DM subjects, and consistently, none of the Lp(a) SNPs were associated with CVD risk or mortality in these diabetic cohorts. The genetic effect of $\mathrm{Lp}(\mathrm{a})$ on CHD risk showed a significant heterogeneity between the diabetic and general population. Their results suggest that diabetes states may attenuate the relation between $\mathrm{Lp}(\mathrm{a})$ and cardiovascular risk.

The potential reasons for an inverse association between $\mathrm{Lp}(\mathrm{a})$ and features of insulin resistance and T2DM are unknown. Some human and animal studies suggest an effect of insulin in reducing Lp(a) levels. For example, Rainwater and Hafner (1998) found an inverse correlation of $\mathrm{Lp}(\mathrm{a})$ levels with fasting insulin and 2-h glucose concentrations in both diabetic and nondiabetic participants. Neele et al. (1999) showed that insulin suppressed apo(a) synthesis by primary cultures of cynomolgus monkey hepatocytes. These data suggest that insulin resistance may be manifested by a lowering of $\mathrm{Lp}(\mathrm{a})$ levels that precedes overt T2DM diagnosis. Thus Lp(a) might be another lipoprotein, that is associated with metabolic syndrome characterized by insulin resistance.

A recently published genome-wide study uncovered wide-spread causal effects of $\mathrm{Lp}(\mathrm{a})$ on overall lipoprotein metabolism, and especially causal associations between $\mathrm{Lp}(\mathrm{a})$ and systemic triglyceride and VLDL metabolism. Lp(a) raising allele rs10455872-G was associated with a smaller diameter of VLDL particles. This allele was also associated with lower concentrations of extra large, large, and medium VLDL particles. Their findings suggest that $\mathrm{Lp}(\mathrm{a})$ synthesis affects overall lipoprotein metabolism, and in particular, the synthesis of large VLDL particles in the liver and thereby the triglyceride metabolism in general. Based on these results, they propose that the apoB-containing lipoprotein particle used to form $\mathrm{Lp}(\mathrm{a})$ by the covalent attachment of apo(a) may actually also be a poorly lipidated VLDL-type particle. This suggests that circulating $\mathrm{Lp}(\mathrm{a})$ particles are likely to be a more heterogeneous group than simply an apo(a) component added to LDL particles (Kettunen et al. 2016).

As triglyceride metabolism is closely associated with insulin resistance, this might also explain inverse association of $\mathrm{Lp}(\mathrm{a})$ with features of insulin resistance, including metabolic syndrome and T2DM.

\section{Conclusion}

Lp(a) levels are inversely associated with features of insulin resistance and metabolic syndrome. The potential reason for this inverse association is not clear. Some human and animal studies suggest an effect of insulin in reducing $\mathrm{Lp}$ (a) levels. These data suggest that insulin resistance may be manifested by a lowering of $\mathrm{Lp}(\mathrm{a})$ levels that precedes overt diagnosis of T2DM. Thus Lp(a) might be another lipoprotein, that is associated with metabolic syndrome characterized by insulin resistance. Causal association of $\mathrm{Lp}(\mathrm{a})$ with systemic triglyceride and VLDL metabolism, as demonstrated recently by the results of genome wide study, might play a role in this association.

\section{Conflict of Interest}

There is no conflict of interest.

\section{Acknowledgements}

Supported by grant MZ ČR - RVO (FNOL 00098892) IP 87-54. 


\section{References}

ALBERTI KG, ECKEL RH, GRUNDY SM, ZIMMET PZ, CLEEMAN JI, DONATO KA, FRUCHART JC, JAMES WP, LORIA CM, SMITH SC JR, ET AL.: Harmonizing the metabolic syndrome: a joint interim statement of the International Diabetes Federation Task Force on Epidemiology and Prevention; National Heart, Lung, and Blood Institute; American Heart Association; World Heart Federation; International Atherosclerosis Society; and International Association for the Study of Obesity. Circulation 120: 1640-1645, 2009.

ALMDAL T, SCHARLING H, JENSEN JS, VESTERGAARD H: The independent effect of type 2 diabetes mellitus on ischemic heart disease, stroke, and death: a population-based study of 13,000 men and women with 20 years of follow-up. Arch Intern Med 164: 1422-1426, 2004.

BENNET A, DI ANGELANTONIO E, ERQOU S, EIRIKSDOTTIR G, SIGURDSSON G, WOODWARD M, RUMLEY A, LOWE GD, DANESH J, GUDNASON V: Lipoprotein(a) levels and risk of future coronary heart disease: large-scale prospective data. Arch Intern Med 168: 598-608, 2008.

BOERWINKLE E, LEFFERT CC, LIN J, LACKNER C, CHIESA G, HOBBS HH: Apolipoprotein(a) gene accounts for greater than $90 \%$ of the variation in plasma lipoprotein(a) concentrations. J Clin Invest 90: 52-60, 1992.

CAMPOS H, BLIJLEVENS E, MCNAMARA JR, ORDOVAS JM, POSNER BM, WILSON PW, CASTELLI WP, SCHAEFER EJ: LDL particle size distribution. Results from the Framingham Offspring Study. Arterioscler Thromb 12: 1410-1419, 1992.

CLARKE R, PEDEN JF, HOPEWELL JC, KYRIAKOU T, GOEL A, HEATH SC, PARISH S, BARLERA S, FRANZOSI MG, RUST S, BENNETT D, SILVEIRA A, MALARSTIG A, GREEN FR, LATHROP M, GIGANTE B, LEANDER K, DE FAIRE U, SEEDORF U, HAMSTEN A, COLLINS R, WATKINS H, FARRALL M; PROCARDIS CONSORTIUM: Genetic variants associated with Lp(a) lipoprotein level and coronary disease. $N$ Engl J Med 361: 2518-2528, 2009.

DANESH J, COLLINS R, PETO R: Lipoprotein(a) and coronary heart disease. Meta-analysis of prospective studies. Circulation 102: 1082-1085, 2000.

De GRAAF J, VAn DER VLEUTEN G, STALENHOEF AF: Diagnostic criteria in relation to the pathogenesis of familial combined hyperlipidemia. Semin Vasc Med 4: 229-240, 2004.

DING L, SONG A, DAI M, XU M, SUN W, XU B, SUN J, WANG T, XU Y, LU J, WANG W, BI Y, NING G: Serum lipoprotein (a) concentrations are inversely associated with T2D, prediabetes, and insulin resistance in a middle-aged and elderly Chinese population. J Lipid Res 56: 920-926, 2015.

DOBIASOVA M, FROHLICH J: The plasma parameter log (TG/HDL-C) as an atherogenic index: correlation with lipoprotein particle size and esterification rate in apoB-lipoprotein-depleted plasma (FER HDL). Clin Biochem 34: 583-588, 2001.

ERQOU S, KAPTOGE S, PERRY PL, DI ANGELANTONIO E, THOMPSON A, WHITE IR, MARCOVINA SM, COLLINS R, THOMPSON SG, DANESH J; EMERGING RISK FACTORS COLLABORATION: Lipoprotein(a) concentration and the risk of coronary heart disease, stroke, and nonvascular mortality. JAMA 302: 412-423, 2009.

FRIEDEWALD WT, LEVY RJ, FREDRICKSON DS: Estimation of the concentration of low density lipoprotein cholesterol in plasma, without use of the preparative ultracentrifuge. Clin Chem 18: 499-502, 1972.

FROHLICH J, DOBIASOVA M: Fractional esterification rate of cholesterol and ratio of triglycerides to HDL-cholesterol are powerful predictors of positive findings on coronary angiography. Clin Chem 49: 1873-1880, 2003.

GUAN W, CAO J, STEFFEN BT, POST WS, STEIN JH, TATTERSALL MC, KAUFMAN JD, MCCONNELL JP, HOEFNER DM, WARNICK R, TSAI MY: Race is a key variable in assigning lipoprotein(a) cutoff values for coronary heart disease risk assessment: the Multi-Ethnic Study of Atherosclerosis. Arterioscler Thromb Vasc Biol 35: 996-1001, 2015.

HAFFNER SM, KARHAPAA P, RAINWATER DL, MYKKANEN L, ALDRETE G JR, LAAKSO M: Insulin sensitivity and Lp(a) concentrations in normoglycemic men. Diabetes Care 18: 193-199, 1995.

KAMSTRUP PR, NORDESTGAARD BG: Lipoprotein(a) concetrations, isoform size, and risk of type 2 diabetes: a Mendelian randomisation study. Lancet Diabetes Endocrinol 1: 220-227, 2013. 
KAMSTRUP PR, BENN M, TYBJAERG-HANSEN A, NORDESTGAARD BG: Extreme lipoprotein(a) levels and risk of myocardial infarction in the general population: the Copenhagen City Heart Study. Circulation 117: 176-184, 2008.

KAMSTRUP PR, TYBJAERG-HANSEN A, STEFFENSEN R, NORDESTGAARD BG: Genetically elevated lipoprotein(a) and increased risk of myocardial infarction. JAMA 301: 2331-2339, 2009.

KETTUNEN J, DEMIRKAN A, WÜRTZ P, DRAISMA HH, HALLER T, RAWAL R, VAARHORST A, KANGAS AJ, LYYTIKÄINEN LP, PIRINEN M, POOL R, SARIN AP, SOININEN P, TUKIAINEN T, WANG Q, ET AL.: Genome-wide study for circulating metabolites identifies 62 loci and reveals novel systemic effects of LPA. Nat Commun 7: 11122, 2016.

KRONENBERG F: Human genetics and the causal role of lipoprotein(a) for various diseases. Cardiovasc Drugs Ther 30: $87-100,2016$.

MARCOVINA SM, GAUR VP, ALBERS JJ: Biological variability of cholesterol, triglyceride, low- and high-density lipoprotein cholesterol, lipoprotein(a), and apolipoproteins A-I and B. Clin Chem 40: 574-578, 1994.

MARZANO L, COLUSSI G, DEL TORRE M, SECHI LA, CATENA C: Relationships of plasma lipoprotein(a) levels with insulin resistance in hypertensive patients. Metabolism 63: 1439-1446, 2014.

MORA S, KAMSTRUP PR, RIFAI N, NORDESTGAARD BG, BURING JE, RIDKER PM: Lipoprotein(a) and risk of type 2 diabetes. Clin Chem 56: 1252-1260, 2010.

NEELE DM, DE WIT EC, PRINCEN HM: Insulin supresses apolipoprotein(a) synthesis by primary cultures of cynomolgus monkey hepatocytes. Diabetologia 42: 41-44, 1999.

NORDESTGAARD BG, CHAPMAN MJ, RAY K, BORÉN J, ANDREOTTI F, WATTS GF, GINSBERG H, AMARENCO P, CATAPANO A, DESCAMPS OS, FISHER E, KOVANEN PT, KUIVENHOVEN JA, LESNIK P, MASANA L, REINER Z, TASKINEN MR, TOKGÖZOGLU L, TYBJÆRG-HANSEN A; EUROPEAN ATHEROSCLEROSIS SOCIETY CONSENSUS PANEL: Lipoprotein(a) as a cardiovascular risk factor: current status. Eur Heart J 31: 2844-2853, 2010.

QI Q, WORKALEMAHU T, ZHANG C, HU FB, QI L: Genetic variants, plasma lipoprotein(a) levels, and risk of cardiovascular morbidity and mortality among two prospective cohorts of type 2 diabetes. Eur Heart J 33: 325-334, 2012.

RAINWATER DL, HAFFNER SM: Insulin and 2-hour glucose levels are inversely related to Lp(a) concentrations controlled for LPA genotype. Arterioscler Thromb Vasc Biol 18: 1335-1341, 1998.

SNIDERMAN AD, CASTRO CABEZAS M, RIBALTA J, CARMENA R, DE BRUIN TW, DE GRAAF J, ERKELENS DW, HUMPHRIES SE, MASANA L, REAL JT, TALMUD PJ, TASKINEN MR: A proposal to redefine familial combined hyperlipidemia - third worshopon FCHL held in Barcelona from 3 to 5 May 2001, during the scientific sessions of the European Society for Clinical Investigation. Eur J Clin Invest 32: 71-73, 2002.

SUNG KC, WILD SH, BYRNE CD: Lipoprotein (a), metabolic syndrome and coronary calcium score in a large occupational cohort. Nutr Metab Cardiovasc Dis 23: 1239-1246, 2013.

UTERMANN G: The mysteries of lipoprotein (a). Science 246: 904-910, 1989.

YE Z, HAYCOCK PC, GURDASANI D, POMILLA C, BOEKHOLDT M, TSIMIKAS S, KHAW KT, WAREHAM NJ, SANDHU MS, FOROUHI NG: The association between circulating lipoprotein(a) and type 2 diabetes: is it causal? Diabetes 63: 332-342, 2014.

ZLATOHLÁVEK L, ZÍDKOVÁ K, VRABLÍK M, HAAS T, PRUSÍKOVÁ M, SVOBODOVÁ H, ČEŠKA R: Lipoprotein(a) and its position among other risk factors of atherosclerosis. Physiol Res 57: 777-783, 2008. 